https://www.journal-imab-bg.org

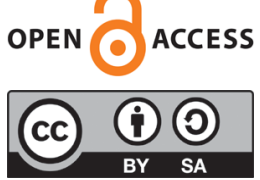

Original article

\title{
DOES THE TEMP-DECISION CONTRIBUTE TO THE RESTORATION OF THE EMPLOYABILITY?
}

\author{
Paraskeva Mancheva \\ Department of Hygiene and Epidemiology, Faculty of Public health, Medical \\ University of Varna, Bulgaria.
}

\section{SUMMARY}

Introduction: A hot topic of the discussions about the reforming of the Territory Expert Medical Commission system (TEMC) is the restoration process of peoples' health and ability to work. The expert decision, given by TEMC offers an opportunity for social adaptation for disabled people, whilst restoring their ability to work, all by using the methods and resources of rehabilitation.

The aim of the article is to study and analyze the opinion of disabled people on the role of the expert's decision by TEMC to restore employability.

Material and Methods: The study's sample was prepared on the basis of the register of General Territory Expert Medical Commission in the Hospital "St. Marina" - Varna. The determination of the population includes preinspection of the register of General TEMC at University Hospital "St. Marina" - Varna and the Regional Cardindex of Medical Expertise (RCME), Varna and covers 6000 patients with disability. A representative sample was formed on the basis of selection criteria and included 612 PD subject to certification and recertification of General Territory Expert Medical Commission at University Hospital "St. Marina" - Varna for the period March-April 2018 , which represents $10.25 \%$ of the population. Amongst the methods of the survey is a questionnaire, consisting of 15 questions in total (13 multiple-choice questions and 2 free-answer questions. The questions are organized in five domains: "organizational-methodical" (questions 2,6 and 7), "social" (questions 3, 5, 8, 9 and 11), "medical" (questions 1 and 4), "juridical" (questions 10, 12 and 13) and "opportunities for change" (questions 14 and 15). Standardized á-Crownbach 0.65 .

Results: Only 4.4\% ( $n=612)$ of the people with disability, determined by TEMC-decision, think that rehabilitation that aims to restore their ability to work is enough. Those of them $(81.9 \%(n=209))$ who've been deprived of their percent for Permanently Diminished Working Capacity, report that they are not following the route of rehabilitation. The patients give different offers: a work recommendation must be included in the TEMC-decision (the type of labour must be synchronized with the given disability); the committee must influence the clinical and social rehabilitation that aims the restoration of temporary or permanent disability.

Conclusions: The TEMC-decision does not help with the achievement of a prophylactic and rehabilitation function of the TEMC nor the restoration of the ability to work. There must be put an emphasis on a few subjects during the reforming process of the TEMCsystem, such as the activities regarding the restoration of work capacity, a prequalification according to the disability and a work recommendation.

Keywords: ability to work, rehabilitation, disability, TEMCdecision

\section{INTRODUCTION}

Solving of the problems of persons with disability is one of the most important priorities in the social policies of European Union member states. The relevance of the problem in Bulgaria is defined by the increase of disability cases under the circumstances of a rapidly ageing population in Bulgaria and the challenges faced by the system of disability medical assessment, the social services and the National Insurance Institute [1].

Socio-economic and political changes after November 1989 changed the way the system of disability medical assessment (DMA) functions. The legislative prerequisites for social rights occur after an expert decision issued by the regional disability medical assessment commissions (DMAC). It is a long and rough way to the acquisition of DMA and works as a barrier to the rights and social integration of persons with disabilities. The complicated situation requires measures for improvement of social and health policies not only on behalf of the governmental but regional level as well. This requires the adoption of a disability strategy which aims complex biological, psychological and social evaluation and rehabilitation for individuals with disabilities, their social inclusion and return to the labour market $[2,3]$.

The reinforcement of the ability to work with a fixed period of rehabilitation as defined by the WHO Rehabilitation Committee (1958) aims at "preventing prolonged disability during the treatment of the disorder and helping disabled people to maximize their physical, mental, professional and socio-economic fullness within the framework of the existing disease or disability". The necessary actions of social policy in this direction can be reduced in general to two fields of action: actions that are directed directly to the person with a disability and closest social environment and actions forming the physical and social sphere [4, 5, 6].

The Bulgarian legislation defines the system of TEMC as an integral part of the diagnostic, medical and prophylactic activities of the medical institutions. TEMC assesses the rate of Permanently Diminished Working Capacity (PDWC), in percent of the healthy person. The expert decision determines the contraindicated working conditions and the persons are recruited at the discretion of the Commission. Properly dosed and well-chosen work is a healingprophylactic factor, but in the TEMC-decision does not determine its parameters, as well as a labour recommendation for a specific type of labour. According to the TEMC-deci- 
sion, the person with inviolability seeks to realize the rights of many institutions, which are related to the rehabilitation process, and occupational rehabilitation [7, 8].

The latter can happen in several ways:

- Adaptation of places of work to the individual characteristics of workers with abilities;

- The realization of projects related to the opening of new jobs for people with injuries;

- Legal protection and labor-related consultations on labor, labor relations and rehabilitation of persons with disabilities;

- Assessment of the occupational, managerial and working capacity of the injured person;

- Development and improvement of the existing legal framework related to the labor rehabilitation of invalides; the disabled.

- Professional qualification and re-qualification of

The aim of the article is to study and analyze the opinion of disabled people on the role of the expert's decision by TEMC to restore employability.

\section{MATERIAL AND METHODS}

The presented study is part of a DSc -research project on "Medico-social problems of handicap in the Medical Expertise System" (main investigator: P. Mancheva MD, PhD, DSc; Protocol/permission from 01. 03. 2018 by Ethical Commission Medical University-Varna) [9]. The empirical study is based on a survey of the opinion of 612 persons with a disability, who were recertified by TEMP by 2017 , live in Varna District and appear in the Register of General TEMC at the University Hospital "St. Marina"- Varna and Regional Card-index of Medical Expertise (RCME). The sample represents $10.2 \%$ of those passed through the Commission for 2017 and is formed according to the inclusion and exclusion criteria.

The study's sample was prepared on the basis of the register of General TEMC in the Hospital "St. Marina" -
Varna. The determination of the population includes preinspection of the register of General TEMC at University Hospital "St. Marina" - Varna and RCME-Varna and covers 6000 patients with disability (PD). A representative sample was formed on the basis of selection criteria and included 612 PD subject to certification and re-certification of General TEMC at University Hospital "St. Marina" - Varna for the period Mart-April 2018, which represents $10.25 \%$ of the population.

The study's inclusion criteria: a certain degree of disability; living in Varna region; appearing in the register of General TEMC at University Hospital "St. Marina” - Varna and RCME-Varna.

The study's exclusion criteria: patients who first appear to TEMC; children.

Instruments - a questionnaire with 15 questions, out of which 13 closed and 2 open (app. 3), was developed by us, especially for this purpose. Questions are organized in the following domains: "organizational-methodical" (questions 2, 6 and 7), "social" (questions 3, 5, 8, 9 and 11), "medical" (questions 1 and 4), "juridical" (questions 10, 12 and 13) and "opportunities for change" (questions 14 and 15) and is of good reliability. The standardized á-Crown back is 0.65 . Statistical processing of the results: The research was developed using the software products MS Excel 2010 and SPSS Version 24.0. Statistical methods used in the processing of the survey data are: statistical grouping of the data; descriptive (descriptive) methods; correlation analysis; nonparametric correlation coefficient of contingency.

\section{RESULTS AND DISCUSSION}

The study included 612 PD people represented by different age groups, gender, degree of disability, education, employment, family status, domicile. The socio-demographic characteristics of the respondents are shown in Table 1:

Table. 1. Socio-demographic characteristics of the respondents $(n=612)$

\begin{tabular}{llcc}
\multirow{3}{*}{ Gender } & & Count & Percent \\
\cline { 2 - 4 } & Man & 316 & 51,6 \\
\cline { 2 - 4 } Age & Female & 296 & 48,4 \\
\hline \multirow{3}{*}{ Degree of disability } & $16-65$ years & 526 & 85,9 \\
\cline { 2 - 4 } & 65+ years & 86 & 14,1 \\
\cline { 2 - 4 } & Yes, over 90\% with help from others & 8 & 1,3 \\
\cline { 2 - 4 } & Yes, over 90\% without help from others & 32 & 5,2 \\
\cline { 2 - 4 } & Yes, from 71 to 90\% & 148 & 24,2 \\
\cline { 2 - 4 } Education & Yes, from 50\% to 70\% & 352 & 57,5 \\
\cline { 2 - 4 } & No, I do not have & 72 & 11,8 \\
\cline { 2 - 4 } & Master degree & 225 & 36,8 \\
\cline { 2 - 4 } & High education & 142 & 23,2 \\
\cline { 2 - 4 } & Vocational education & &
\end{tabular}




\begin{tabular}{lcc}
\hline Primary education & 92 & 15 \\
\hline With employment & 220 & 35,9 \\
\hline Retired & 144 & 23,5 \\
\hline No employment & 248 & 40,5 \\
\hline Married & 392 & 64,1 \\
\hline Unmarried & 75 & 12,3 \\
\hline Divorced & 87 & 14,2 \\
\hline Widow & 58 & 9,5 \\
\hline Village & 139 & 22,7 \\
\hline Small town & 103 & 16,8 \\
\hline Big city & 5 & 0,8 \\
\hline District town & 365 & 59,6 \\
\hline Total & 612 & 100
\end{tabular}

The distribution of respondents by gender is almost equal - $51.6 \%$ men and $48.4 \%$ women. People predominant in the age range of 16-65 years are $85.9 \%$, and only $14.1 \%$ are over 65 years old. More than half of the respondents $(57.5 \%)$ have a fixed PDWC rate of 50 to $70 \%$, $24.2 \%$ are 71 to $90 \%$, and only $6.5 \%$ are over $9 \%-1.3 \%$ with foreign help and 5, 2\% without help. At $11.8 \%$, the PDWC rate was cancelled at the last re-certification. Without employment, they are $40.5 \%$, working $35.9 \%$ and $23.5 \%$ - retirees on retirement age and age. The respondents in $64.1 \%$ are family members, and $59.6 \%$ live in a district town. The analysis of the demographic indicators of the persons included in the representative sample al- lows getting an idea of the characteristics of this vulnerable group from the community in the Varna region. In $85.9 \%$, these are persons of working age (16 to 65 years old), who are $64.1 \%$, living in a regional town at $59.6 \%$ and without hard work at $40.5 \%$.

TEMC's in their decisions set out recommendations for further monitoring and rehabilitation of patients in compliance with Article 61 (2) (5) of the Ordinance on medical expertise, which provoked us to investigate the opinion of those concerned about the application of this legal option $[10,11]$. Persons with PDWC only in $5.0 \%$ of all respondents and $4.4 \%$ of all respondents in the study consider that rehabilitation is sufficient (Table 2):

Table. 2. Degree of disability

Your rehabilitation after the TEMP decision was:

\begin{tabular}{|c|c|c|c|c|c|c|}
\hline & & & Sufficient & Insufficient & $\begin{array}{l}\text { They did not direct } \\
\text { me for rehabilitation }\end{array}$ & Total \\
\hline \multirow{4}{*}{$\begin{array}{l}\text { Degree of } \\
\text { disability }\end{array}$} & \multirow{2}{*}{$\begin{array}{l}\text { With degree of } \\
\text { disability }\end{array}$} & Count & 27 & 304 & 209 & 540 \\
\hline & & Percent & 5 & 56,3 & 38,7 & 100 \\
\hline & \multirow{2}{*}{$\begin{array}{l}\text { Without degree of } \\
\text { disability }\end{array}$} & Count & 0 & 13 & 59 & 72 \\
\hline & & Percent & 0 & 18,1 & 81,9 & 100 \\
\hline & \multirow[t]{2}{*}{ Total } & Count & 27 & 317 & 268 & 612 \\
\hline & & Percent & 4,4 & 51,8 & 43,8 & 100 \\
\hline
\end{tabular}

Those who were discontinued at the PDWC rate at the last re-enhancement in $81.9 \%$ said they were not rehabilitating. The review of European experience in this direction reveals opportunities for these patients, but in Bulgarian terms, the law does not provide access to invalidity pension, tax relief, social privileges, incl. medical and social rehabilitation. Perhaps it is necessary to provide for a less restrictive regime for social adaptation for persons below 50\% PDWC. Of the 144 persons retired in retirement age and 59 per cent state that they are not rehabilitated as a result of the TEMC decision, they have received. Inadequate rehabilitation 129 of 220 workers $(58.63 \%)$ with a disability and $52.82 \%$ of respondents without employment (131 out of 248 persons without employment) were considered insufficient. The Disability Rehabilitation Strategy contains a synchronized and combined application of three groups of measures: medical, social and occupational. The team involvement of all the institutions responsible for the implementation of these events (Ministry of Health, Ministry of Labor and Social Policy, National Social Security Institute, Agency for Social Assistance, TEMC, National Expert Medical Commis- 
sion, rehabilitation centers, etc.) in order to achieve the general goal - not only to enable people with disabilities to be socially involved but also to involve and adapt society and to accept disability as an inevitable but not insurmountable phenomenon.
Asked, "What do you want to change in legislation to improve physical recovery?" $41.4 \%$ of disabled employees respond that "rehabilitation should be in accordance with the condition of the sick person" - more often and as much as necessary Table 3):

Table. 3. Employment

\section{What do you want to change in legislation to} improve physical recovery

\begin{tabular}{|c|c|c|c|}
\hline 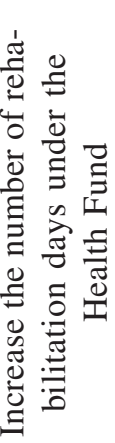 & 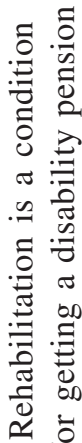 & 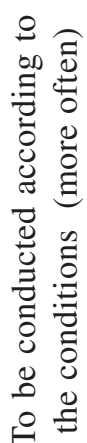 & 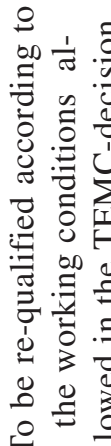 \\
\hline
\end{tabular}

\begin{tabular}{llllllll}
\hline \multirow{4}{*}{$\begin{array}{l}\text { Degree of } \\
\text { Employment }\end{array}$} & $\begin{array}{l}\text { With } \\
\text { employment }\end{array}$ & Count & 54,0 & 21,0 & 91,0 & 54,0 & 220,0 \\
\cline { 2 - 8 } & Retired & Count & 58,0 & 6,0 & 65,0 & 15,0 & 144,0 \\
\cline { 2 - 8 } & & Percent & 40.3 & 4,2 & 45.1 & 10,4 & 100.0 \\
\cline { 2 - 8 } & Without & Count & 74,0 & 9,0 & 93,0 & 72,0 & 248,0 \\
\cline { 2 - 8 } & employment & Percent & 29,8 & 3,6 & 37.5 & 29.0 & 100.0 \\
\hline \multirow{2}{*}{ Total } & Count & 186,0 & 36,0 & 249,0 & 141,0 & 612,0 \\
\cline { 2 - 8 } & & Percent & 30,4 & 5,9 & 40.7 & 23.0 & 100.0
\end{tabular}

Pensioners maintain the same opinion in this respect in $45.1 \%$, as well as $37.5 \%$ of people without employment. Only $9.5 \%$ of surveyed workers consider that rehabilitation should be a clause for receiving a disability pension. Therefore, after receiving the medical checkbook for their health status from the TEMC system, the respondents do not seek to restore their working capacity and return to the labor market, but they have to face the social benefits of the TEMC expert's decision.

It is assumed that the medical and social assessment contributes to positive changes in the situation of persons with disability, but when monitoring the respondents' answers to this question, we find that 253 persons with a certain degree of disability (46.9\% of all 540 persons with PDWC in the study) report a lack of change, $28.15 \%$ "has improved" and only 5.93\% - "has deteriorated". The remaining 72 respondents have no fixed percentage of PDWC, so they have not received a social assessment and have not realized rights. Their self-esteem is that in $44.44 \%$ their situation is the same, and even in $40.28 \%$ has worsened (Table 4):

Table 4. Disability

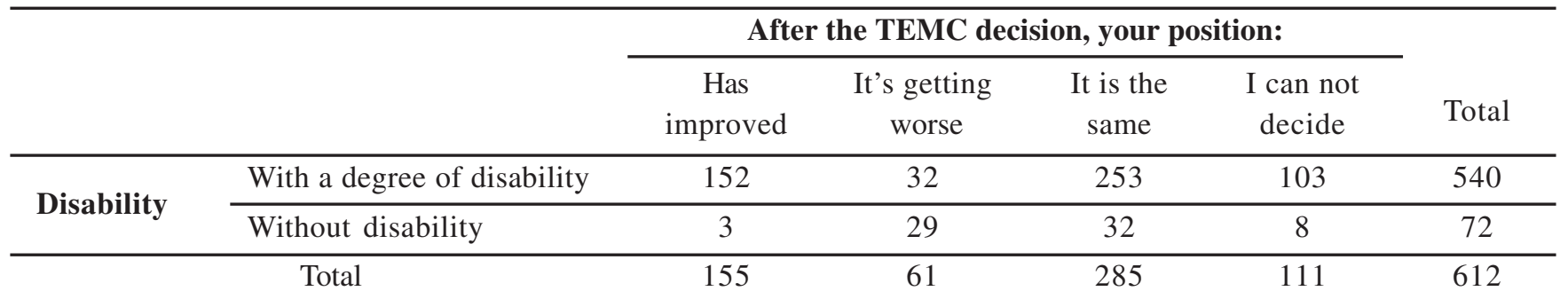


Conclusions to be made:

1. Individuals with PDWC defined by the TEMC decision - only $4.4 \%(n=612)$ consider that the rehabilitation is sufficient.

2. Those who have been discharged PDWC at the last re-accrual at $81.9 \%(n=209)$ report that they are not targeted for occupational rehabilitation;

3 . For lack of social adaptation after the TEMC decision, incl. returning to work ability, reported $46.9 \%$ of all 540 persons with a certain degree of disability.

In connection with the forthcoming reforms in the OेEMC, the respondents put forward the following proposals for change: An integral part of the TEMC-decision is the labor recommendation for the type of work, consistent with the disability; committees to assist clinical and social rehabilitation to restore temporary and permanent disability.

\section{CONCLUSION}

The problems of people with disabilities and the realization of their rights are directly related to the functioning of TEMC, and the expert decision of the Commissions is a necessary condition for the social adaptation and return of the ability to work. Reluctant people consider the rehabilitation funded by the National Health Insurance Fund to be insufficient, seeking social benefits and disability pensions. It is worrying that there is a lack of positive change in their social status and employability after the TEMC decision, even though the legally established rights under it have been fully implemented [12].

The situation of people with disabilities in Bulgaria, as an equal member of the European Union, requires that these issues be solved in the light of world leaders.

Attempts for solving the problem by legislation changes do not clarify the range of people affected and slow down the process of social integration of the people concerned. The system of disability medical assessment faces negative consequences as its occupation and professional, preventive and rehabilitation function is often overlooked. Government and the society are trying to create conditions for a fair distribution of health and social resources by intermittent reforms in the system of disability medical assessment aiming to strengthen of the social benefits.

\section{REFERENCES:}

1. Slavova V. Contemporary medicine - science or art? Philosophy. 2019; 28(2):128-134.

2. Nenova G, Mancheva P. Physiotherapy and chronic diseases. LAP Lambert Academic Publishing. 2016. $44 \mathrm{pp}$.

3. Petrova G, Kostadinova T, Georgieva E, Nenova G, Raykov T. Application of management programs for chronic diseases - international experience and situation in Bulgaria. International Scientific and Practical Conference "World Science". 2016; 2(6)3:24-27.

4. Haralampiev K. Disability in Bulgaria - Ten Years Later. European Population Conference. Stockholm; 2012.

5. Mancheva P, Vankova D. Preparing patients for handicap-stage assessment and the challenges for the
General medical practice. Scripta Scientifica Salutis Publicae. 2015; 1(1):45-51.

6. Murray CG, Barber RM, Foreman KJ, Abbasoglu Ozgoren A, Abd-Allah F, Abera SF, et al. Global, regional, and national disability-adjusted life years (DALYs) for 306 diseases and injuries and healthy life expectancy (HALE) for 188 countries, 1990-2013: quantifying the epidemiological transition. The Lancet. 2015 Nov 28;386(10009): 2145-91. [PubMed] [Crossref]

7. The European Union Disability Strategy. [Internet]

8. Shakespeare T. Disability rights and wrongs revisited. London; 2014. 296 pp.

9. Mancheva P. The functioning of the territorial expert medical commission and rehabilitation of disability - the experts' opinion. Scripta Scientifica Salutis Publicae. 2019; 5:7-13.

10. Ordinance on medical expertise. State Gazette (official edition of the National Assembly), issue 51 on 27. 06. 2017/last changes: State Gazette, issue 64 from 08.03.2018. [in Bulgarian]

11. Health law. State Gazette (official edition of the National Assembly), issue 70 on 10. 08. 2004/ last changes: State Gazette, issue 24 from 22. 03. 2019. [in Bulgarian]

12. Mancheva P, Nenova G. [Medical-social rehabilitation and integration of patients with disabilities.] International Scientific and Practical Conference "Synthesis of science and society in solving global problems of our time". "Omega Science". 2016;(2):235239. [in Russian]

Please cite this article as: Mancheva P. Does The Temp-Decision Contribute to The Restoration of The Employability? J of IMAB. 2020 Jan-Mar;26(1):2921-2925. DOI: https://doi.org/10.5272/jimab.2020261.2921

\section{Address for correspondence:}

Prof. Dr Paraskeva Mancheva, MD, Msc, PhD; Department of Hygiene and Epidemiology, Faculty of Public health, Medical University of Varna,

55, Marin Drinov Str., 9002 Varna, Bulgaria

e-mail: p_mancheva@abv.bg 